$\mathbf{R}_{\text {ESEARCH }} \mathbf{P}_{\text {APER }}$

FOOD SCIENCE RESEARCH JOURNAL

\title{
Effect of different levels of paneer whey on quality of carrot Halwa
}

\author{
J. DAVID
}

\begin{abstract}
A study was undertaken by utilizing different levels of Paneer whey (i.e. $0.5 \%, 1 \%$ and $1.5 \%$ ) for manufacturing of good quality carrot Halwa. Grated carrot and a mixture of Ghee, sugar, cardamom, cashewnut were used as other ingredients. The quality of Halwa was highly influenced by carrot and their concentration in whey. Whey greatly improved the shelf-life of carrot Halwa. The product was analyzed for organoleptic attributes (colour and appearance, body and texture, flavour and taste) by trained panelist using 9 point hedonic scale. Chemical (Fat, protein, carbohydrate) and microbiological (SPC, Coliform, Yeast and mold count) analysis were done for estimating its nutritional content and shelf-life. As per as product overall acceptability judged by the panelist, the treatment can be rated as $\mathrm{T}_{3}>\mathrm{T}_{2}>\mathrm{T}_{1}>$ $\mathrm{T}_{1}$.
\end{abstract}

Key Words : Paneer, Whey, Shelf-life, Carrot Halwa

How to cite this article : David, J. (2015). Effect of different levels of paneer whey on quality of carrot Halwa. Food Sci. Res. J., 6(1): 132-134.

Email: profjohndavid06@gmail.com 